\title{
Definiciones operativas y protocolo anestésico durante la pandemia producida por SARS-CoV-2 en un programa de cirugía cardíaca pediátrica
}

\author{
Operative definitions and anesthetic protocol during the \\ SARS-CoV-2 pandemic in a pediatric cardiac surgery program
}

Lourdes Pellecer González, MD11, Orlando Tamariz-Cruz, MD¹,

\begin{abstract}
The clinical characteristics of the pediatric population infected with the SARS-CoV-2 virus in general are not as severe as in the adult population, so they can be considered asymptomatic carriers. The pediatric patient with congenital heart disease are considered a high risk group of contagion in the SARS-CoV-2 pandemic, so healthcare personnel who interact with patients must have established guidelines to avoid transmission and spread of the disease. Each country is commanded by the central guidelines established by its health system considering operative definitions and protocols, but in certain places these guidelines do not fulfill international standards, as those proposed by the World Health Organization. In this communication we have done a current literature review and adaptation of the recommendations to face the infectious outbreak due to the SARS-CoV-2 virus in pediatric cardiovascular surgery programs, specifically in the anesthesiology area. We also analyze the type of personal protective equipment that should be used in each area of patient management, changes in the environment of work areas, shift times of health personnel, the protection of personnel performing transesophageal echocardiography, modification of the airway management algorithms, proper placement and withdrawal of personal protective equipment, patients transfer between wards or other services, and adequate disinfection of airway equipment used.
\end{abstract}

\section{Key words:}

Airway, anesthesia, pediatric cardiovascular anesthesia, personal protective equipment, COVID-19, SARS-CoV-2

Servicio de Anestesia Cardiovascular Pediátrica, Centro Pediátrico del Corazón ABC-KARDIAS. México.

División de Cirugía Cardiovascular, Instituto Nacional de Pediatría. México.

Fecha de recepción: 12 de abril de 2020

Fecha de aceptación: 12042020

\section{ORCID}

https://orcid.org/0000-0001-7811-8402

Correspondencia:

Lourdes Carolina Pellecer González

Email: Ipellecer@hotmail.com 


\section{RESUMEN}

Las características clínicas de la población pediátrica contagiada del virus SARS-CoV-2 en general no son tan severas como en la población adulta, por lo que pueden ser considerados portadores asintomáticos. El paciente pediátrico con cardiopatía congénita pertenece a un grupo de alto riesgo de contagio dentro de la pandemia producida por el SARS-CoV-2, por lo que el personal sanitario que interactúe con los pacientes debe tener lineamientos establecidos para evitar la transmisión y propagación de la enfermedad. Cada país se rige por las guías centrales establecidas por su sistema de salud en cuanto a definiciones operativas y protocolos, pero en algunos lugares estas directrices no cumplen las metas internacionales, como las propuestas por la Organización Mundial de la Salud. En este comunicado hemos realizado una revisión de la literatura actual y adaptación de las recomendaciones para enfrentar el brote infeccioso por el virus SARSCoV-2 en los programas de cirugía cardiovascular pediátrica, específicamente en el área de anestesiología. También analizamos el tipo de equipo de protección personal que debe ser utilizado en cada área del manejo de pacientes, cambios del ambiente de las áreas de trabajo, rotación de personal, la protección del personal que realiza ecocardiografía transesofágica, modificación de los algoritmos de manejo de la vía aérea, colocación y retiro correctos del equipo de protección personal, traslado de los pacientes entre servicios, y adecuada desinfección del equipo utilizado en el manejo de la vía aérea.

\section{Palabras clave:}

Vía aérea, anestesia, anestesia cardiovascular pediátrica, equipo de protección personal, COVID-19, SARS-CoV-2

\section{Introducción}

M undialmente la pandemia por SARS-CoV-2 ha generado un cambio en las conductas y rutinas en todos los niveles de las diferentes actividades productivas. La mayor parte de países han incrementado las medidas de aislamiento con la finalidad de contener los contagios, pero sin modificaciones sustanciales en cuanto al personal considerado esencial, como lo es el de la salud. Debido a que, salvo condiciones específicas como la existencia de comorbilidades (diabetes, hipertensión, embarazo o puerperio y condiciones que inducen inmunosupresión), el personal de salud atenderá urgencias tanto en las áreas clínicas como quirúrgicas, es conveniente establecer pautas con relación a las acciones que se deben tomar al atender a los pacientes, y delimitar los momentos en los que se debe emplear equipos de protección personal (EPP) y su adecuada colocación[1].

La Confederación Latinoamericana de Sociedades de Anestesiología, la Asociación Americana de Anestesiología, la Sociedad Europea de Anestesiología y la Federación Mundial de Sociedades de Anestesiología recomiendan la provisión y uso adecuado de EPP a todo el personal sanitario expuesto a pro- cedimientos de alto riesgo de contagio; asimismo, la Asociación de Hospitales Infantiles de los Estados Unidos, recomienda cubrir las necesidades básicas para el cuidado de casos pediátricos complejos (como la cirugía cardiovascular pediátrica) relacionados o no con COVID-19[2],[3].

Este documento tiene como objetivo homogeneizar el adecuado manejo de pacientes operados de cirugía cardíaca pediátrica, con una revisión de la literatura actual y bajo el entendido que las recomendaciones pueden ser adaptadas a diferentes programas para mejorar el manejo de estos pacientes durante la epidemia, con atención especial a la seguridad del personal sanitario.

\section{Clasificación de procedimientos quirúrgicos pediátricos}

Una de las estrategias para el enfrentamiento de la pandemia producida por el virus SARS-CoV-2 ha sido habilitar hospitales denominados "Centros COVID-19", diseñados para la atención de pacientes que padecen esta patología. Mientras que en los hospitales "NO COVID-19" la atención se dirige a pacientes sin sospecha de la enfermedad, 
con intervenciones o procedimientos de urgencia quirúrgica.

La Asociación de Hospitales Infantiles de los Estados Unidos define grupos de urgencia quirúrgica en la población pediátrica, diferencia dos subgrupos, "asintomáticos" que se refiere a la ausencia de síntomas respiratorios y "sintomáticos" la presencia de estos. Se recomienda operar a los grupos 2b, 3a y 3b[4] (Tabla 1).

\section{Definición epidemiológica de caso sospechoso y confirmado para el virus SARS-CoV-2}

La definición de caso sospechoso varía en relación con el nivel de alerta epidemiológica de cada región. En el nivel de alerta epidemiológica 1 el principal foco de contagio son los casos importados, su definición cuenta con criterios epidemiológicos y clínicos (Tabla 2).

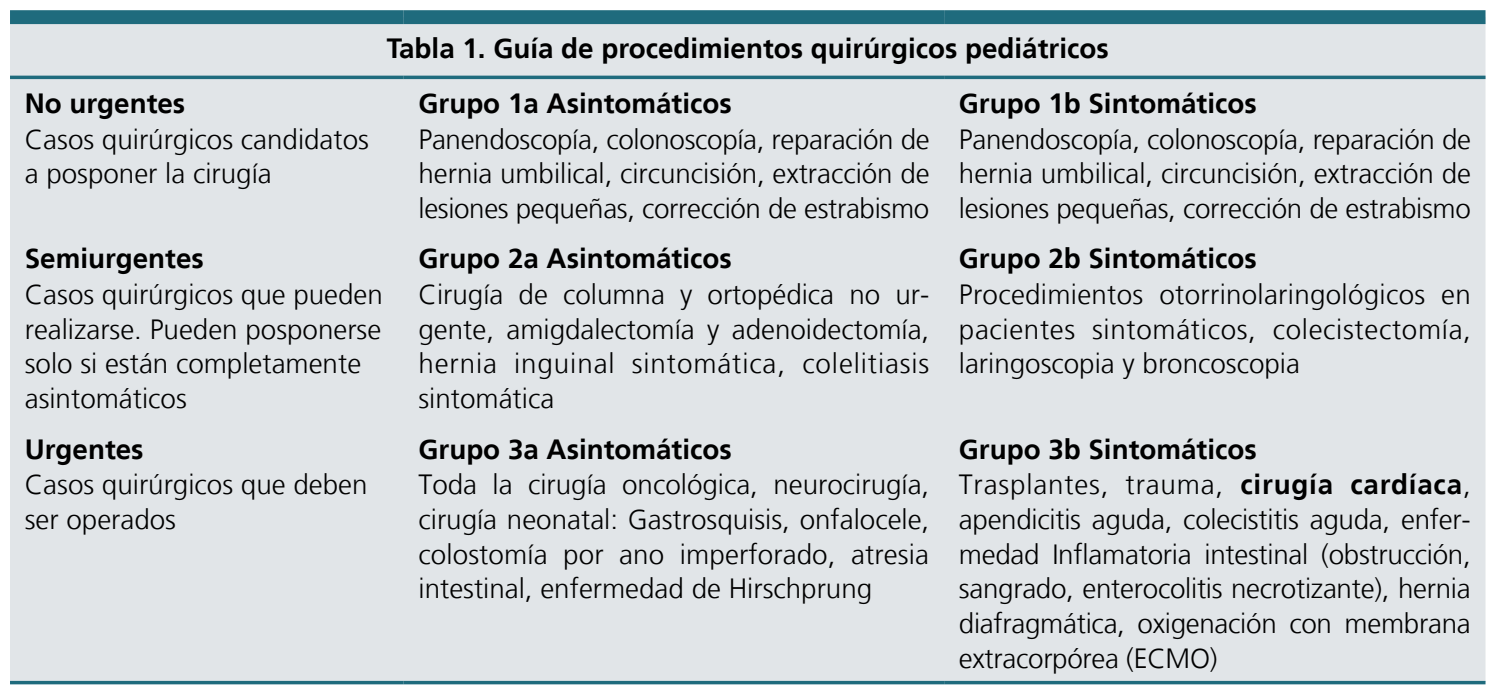

Fuente: Modificado de The Children's Hospital Association of the United States. Pediatric Elective Surgery/Procedure Guidance[4].

\section{Tabla 2. Definición de caso sospechoso en nivel epidemiológico 1}

\section{Criterios clínicos:}

1. Fiebre, fatiga, tos seca; algunos pacientes pediátricos pueden no tener fiebre

2. Pacientes con los siguientes hallazgos de imágenes de tórax: múltiples sombras pequeñas irregulares y cambios intersticiales, principalmente en la periferia pulmonar, opacidad bilateral de múltiples agallas de tierra, sombras infiltrantes, consolidación pulmonar en la radiografía de tórax u opacidades de vidrio esmerilado, consolidación pulmonar segmentaria bilateral, especialmente en la periferia en la TC de tórax

3. Los recuentos de glóbulos blancos son normales o disminuidos, o con un recuento disminuido de linfocitos

\section{Criterios epidemiológicos:}

1. Niños con antecedentes de viaje o residencia en la ciudad de Wuhan y áreas vecinas, u otras áreas con transmisión local persistente dentro de los 14 días previos al inicio de la enfermedad

2. Niños con antecedentes de contacto con pacientes con fiebre o síntomas respiratorios que tienen antecedentes de viaje o residencia en la ciudad de Wuhan y áreas vecinas, o en otras áreas con transmisión local persistente dentro de los 14 días previos al inicio de la enfermedad

3. Niños con antecedentes de contacto con casos confirmados o sospechosos de SARS-CoV-2 dentro de los 14 días previos al inicio de la enfermedad

4. Niños relacionados con un brote: además de este paciente, hay otros pacientes con fiebre o síntomas respiratorios, incluidos casos sospechosos o confirmados infectados con SARS-CoV-2

5. Recién nacidos con madres sospechosas o confirmadas de infección por SARS-CoV-2

Son requeridos dos criterios clínicos y uno epidemiológico. Fuente: Tomado de Case definition by the National Clinical Research Center for Child Health, Zhejiang University School of Medicine. 
En el nivel de alerta epidemiológica 2, el principal foco epidemiológico es el caso comunitario, su definición enfatiza en el uso de criterios clínicos, con o sin criterios epidemiológicos (Tabla 3).

La Universidad de Zhejiang define caso confirmado como una muestra de hisopeado de garganta, esputo, heces o sangre con resultado positivo para SARS-CoV-2 bajo las técnicas de RT-PCR, secuenciación genética o cultivo[5],[6].

\section{Agentes biocidas que inactivan el virus SARS-CoV-2}

El virus SARS-CoV-2 se inactiva al utilizar solventes lipídicos como etanol > 75\% (alcohol etílico), isopropanol $>70 \%$ (alcohol isopropílico), formaldehído $>0,7 \%$, povidona yodada $>0,23 \%$, hipoclorito de sodio $>0,21 \%$ (cloro) y peróxido de hidrógeno $>0,5 \%$ (agua oxigenada). La clorhexidina 0,02\% no ha mostrado efectividad 6.

\section{Equipo de protección personal (EPP)}

Los pacientes pediátricos infectados con SARSCoV-2, tienen cuadros leves e inespecíficos, que en su mayoría pueden pasar desapercibidos. Hasta un 15\% de pacientes pediátricos pueden ser asintomáticos. Todos los procedimientos quirúrgicos mayores, como

Tabla 3. Definición de caso sospechoso en nivel epidemiológico 2

\begin{tabular}{l} 
Criterios mayores en los últimos 7 días \\
Tos \\
Fiebre \\
Cefalea (irritabilidad en $<5$ años) \\
Criterios menores \\
Disnea \\
Artralgias \\
Mialgias \\
Odinofagia \\
Rinorrea \\
Conjuntivitis \\
Dolor torácico \\
\hline
\end{tabular}

Son requeridos dos criterios mayores y un criterio menor. Fuente: El Instituto de Diagnóstico y Referencia Epidemiológicos de México (InDRE) modificado el 25 de marzo de 2020. la cirugía cardiotorácica, son considerados procedimientos de alto riesgo para la infección del personal sanitario y es recomendado utilizar EPP según la exposición del personal sanitario[5]-[7] (Tabla 4).

\section{Tipo de equipo de protección personal}

- Respiradores de máscara facial de filtro clase 3 (FFP3), clase 2 (FFP2), N95

Los respiradores son mascarillas de alta eficiencia que se usan para evitar la inhalación de pequeñas partículas en el aire (aerosol). Debe ajustarse a la cara del usuario, y cubrir tanto la nariz como la boca. No se debe colocar alrededor del cuello del usuario después de su uso. No debe ser tocado una vez puesto.

Los respiradores FFP3 filtran al menos el 99\% de las partículas en el aire, los FFP2 y los N95 filtran al menos el $94 \%$ y el $95 \%$ respectivamente, y pueden usarse si los respiradores FFP3 no están disponibles[9].

La verificación del ajuste y compatibilidad con otro EPP (gafas protectoras, careta) debe realizarse previamente a su uso[5].

Los respiradores son de un solo uso y se desechan según la norma hospitalaria de desechos infecciosos. Debido a la escasez de EPP se puede considerar su reutilización según las instrucciones del fabricante y recomendaciones de cada centro hospitalario.

Reemplazar en cualquiera de las siguientes circunstancias[9]:

- Está dañado, roto o maltratado.

- Está sucio (secreciones, fluidos corporales, etc.)

- Está húmedo.

- El sello facial está comprometido.

- Es incómodo.

- Es difícil respirar.

\section{- Mascarillas quirúrgicas resistentes a fluidos}

Las máscaras quirúrgicas resistentes a los fluidos (Tipo IIR) (FRSM) brindan protección de barrera contra las gotas respiratorias (droplets) que alcanzan la mucosa de la boca y la nariz. Deben ajustarse y cubrir nariz y boca adecuadamente. Son para uso individual durante un solo procedimiento. Deben desecharse según la norma hospitalaria de desechos bioinfecciosos, y no deben estar sujetas a uso continuo en ninguna de las circunstancias descritas para los respiradores[9].

El efecto protector de las mascarillas contra el síndrome respiratorio agudo severo (SRAS) y otras infecciones virales respiratorias ha sido bien establecido. No hay evidencia de que los respiradores agreguen valor sobre las mascarillas para la protección de gotas cuando se utilizan con otros aditamentos de EPP e higiene de manos, excepto en el contexto de los procedimientos generadores de aerosol[9]. 
Tabla 4. Equipo de protección personal, momentos clínicos y características de integración de acuerdo a la definición epidemiológica

\begin{tabular}{|c|c|c|c|}
\hline \multicolumn{4}{|c|}{ Paciente asintomático y sin exposición de riesgo } \\
\hline Lugar & Personal & Actividad & EPP \\
\hline \multirow{2}{*}{$\begin{array}{l}\text { Consulta/Evaluación/ } \\
\text { Encamamiento }\end{array}$} & Paciente y acompañante & Cualquier actividad & Mascarilla quirúrgica \\
\hline & Personal sanitario & Cualquier actividad & $\begin{array}{c}\text { Mascarilla quirúrgica } \\
\text { Bata } \\
\text { Guantes } \\
\text { Protección ocular }\end{array}$ \\
\hline \multirow[t]{2}{*}{$\begin{array}{l}\text { Quirófano o terapia } \\
\text { intensiva }\end{array}$} & Paciente & $\begin{array}{c}\text { Previo a manipulación de la } \\
\text { vía aérea }\end{array}$ & Mascarilla quirúrgica \\
\hline & Personal sanitario & $\begin{array}{c}\text { Manipulación de vía aérea: } \\
\text { Entubación, recolocación } \\
\text { de TOT, ETE, extubación, } \\
\text { broncoscopía, otros }\end{array}$ & $\begin{array}{c}\text { Doble gorro } \\
\text { Respirador N95 } \\
\text { Protección ocular } \\
\text { Bata } \\
\text { Doble guante } \\
\text { Botas }\end{array}$ \\
\hline \multirow[t]{2}{*}{$\begin{array}{l}\text { Quirófano o terapia } \\
\text { intensiva }\end{array}$} & Paciente & $\begin{array}{l}\text { Cualquier actividad que no } \\
\text { manipule la vía aérea }\end{array}$ & Mascarilla quirúrgica \\
\hline & Personal sanitario & $\begin{array}{l}\text { Cualquier actividad que no } \\
\text { manipule la vía aérea }\end{array}$ & $\begin{array}{c}\text { Doble gorro } \\
\text { Respirador N95 } \\
\text { Protección ocular } \\
\text { Bata } \\
\text { Doble guante } \\
\text { Botas }\end{array}$ \\
\hline \multicolumn{4}{|c|}{ Caso sospechoso (paciente sintomático y/o con exposición de riesgo) o caso positivo } \\
\hline Lugar & Personal & Actividad & EPP \\
\hline \multirow{2}{*}{$\begin{array}{l}\text { Consulta/Evaluación/ } \\
\text { Encamamiento }\end{array}$} & Paciente y acompañante & Cualquier actividad & Mascarilla N95 \\
\hline & Personal sanitario & Cualquier actividad & $\begin{array}{c}\text { Doble gorro } \\
\text { Respirador N95 } \\
\text { Protección ocular } \\
\text { Bata } \\
\text { Doble guante }\end{array}$ \\
\hline \multirow[t]{2}{*}{$\begin{array}{l}\text { Quirófano o terapia } \\
\text { intensiva }\end{array}$} & Paciente & $\begin{array}{c}\text { Previo a manipulación de la } \\
\text { vía aérea }\end{array}$ & Mascarilla N95 \\
\hline & Personal sanitario & $\begin{array}{l}\text { Manipulación de vía aérea: } \\
\text { Entubación, recolocación } \\
\text { de TOT, ETE, extubación, } \\
\text { broncoscopía, otros }\end{array}$ & $\begin{array}{c}\text { Doble gorro } \\
\text { Respirador N95 } \\
\text { Protección ocular } \\
\text { Bata } \\
\text { Doble guante } \\
\text { Botas }\end{array}$ \\
\hline \multirow[t]{2}{*}{$\begin{array}{l}\text { Quirófano o terapia } \\
\text { intensiva }\end{array}$} & Paciente & $\begin{array}{c}\text { Cualquier actividad que no } \\
\text { manipule la vía aérea }\end{array}$ & Mascarilla N95 \\
\hline & Personal sanitario & $\begin{array}{l}\text { Cualquier actividad que no } \\
\text { manipule la vía aérea }\end{array}$ & $\begin{array}{c}\text { Doble gorro } \\
\text { Respirador N95 } \\
\text { Protección ocular } \\
\text { Bata } \\
\begin{array}{c}\text { Doble guante } \\
\text { Botas }\end{array}\end{array}$ \\
\hline
\end{tabular}

Abreviaturas: EPP: equipo de protección personal, TOT: tubo orotraqueal, ETE: ecocardiograma transesofágico. Fuente: Modificado de: OMS "Rational use of personal protective equipment for coronavirus disease 2019" 2020. CDC "Interim Infection Prevention and Control Recommendations for Patients with Suspected or Confirmed Coronavirus Disease 2019 in Healthcare Settings" 2020[5]-[8]. 


\section{- Protección facial y ocular (PFO)}

La protección de barrera facial y ocular brinda protección contra la contaminación de los ojos por las gotas respiratorias, los aerosoles y las salpicaduras de secreciones (sangre, fluidos corporales o excreciones[9].

La PFO se logra mediante el uso de cualquiera de los siguientes:

- Mascarilla quirúrgica con visera integrada.

- Visera completa o visor.

- Gafas de seguridad de policarbonato o equivalente.

- Las gafas correctivas regulares no se consideran protección ocular adecuada[9].

Mientras se realizan procedimientos generadores de aerosol, se recomienda una pantalla o visera completa[7]-[11].

La PFO se descartará según la norma hospitalaria de desechos bioinfecciosos si es de un solo uso, y si es reutilizable se desinfectará según las instrucciones del fabricante y recomendaciones de cada centro hospitalario.

\section{- Batas desechables}

Las batas repelentes de fluidos desechables (trilaminar de polipropileno) y de manga larga se emplearán cuando existe el riesgo de salpicaduras de fluidos corporales (aerosol o gotas). Si se usan batas no impermeables, se debe usar un delantal de plástico desechable encima[9].

Los delantales desechables y las batas repelentes de fluidos desechables de manga larga son de un solo uso y se descartarán según la norma hospitalaria de desechos bioinfecciosos.

\section{- Guantes desechables}

Se utlizarán guantes desechables en la atención directa del paciente y cuando se anticipe exposición a sangre $u$ otros fluidos corporales. Los guantes desechables son de un solo uso y deben desecharse inmediatamente después de completar un procedimiento y después de cada contacto con el paciente.

\section{Ambiente recomendado para colocación y retiro del EPP}

\section{- Cambio de ropa}

Cada servicio designará un área adecuada para que el personal sanitario cambie su ropa al ingresar al hospital por uniformes limpios brindados por cada servicio, con la finalidad de limitar los fomites dentro y fuera del área hospitalaria. Así mismo, el personal disminuirá el uso de bolsas, carteras, equipo electrónico u otro fomite dentro del área hospitalaria[8],[9].

\section{- Acceso a duchas}

El hospital proveerá áreas adecuadas para duchas del personal sanitario[9].

\section{- Limitar área contaminada/descontaminada}

Serán separadas visiblemente las áreas donde el personal se colocará y retirará el EPP, con la finalidad de evitar la contaminación y mejorar el manejo de desechos bioinfecciosos. Ambas áreas contarán con un sitio para que el personal se pueda sentar, depósitos especiales para descartar el EPP y espacio suficiente para que la actividad se pueda realizar en parejas sin contacto entre las dos personas con un mínimo de 2 metros de distancia entre ellas. Estas áreas también tendrán un lugar para realizar lavado de manos adecuado[8],[9].

\section{- Acceso a soluciones para higiene de manos}

Se recomienda la colocación de dispensadores de soluciones antisépticas con alcohol etílico > 75\% o alcohol isopropílico > 70\% en las áreas de colocación y retiro de EPP para poder realizar la higiene de manos adecuada[5],[9].

\section{Colocación sistemática del EPP}

Se recomienda el uso de la lista de verificación en todos los pasos, misma que se encontrará en un lugar visible dentro del área designada para la colocación del EPP, así como realizar la colocación en parejas para optimizar la verificación de los pasos[8],[9],[11]-[15].

\section{- Equipo necesario}

- Solución antiséptica para higiene de manos.

- Botas.

- Gorro.

- Bata.

- Guantes con tallas disponibles.

- Visor.

- Gafas.

- Respirador de alta eficiencia.

\section{- Antes de la colocación}

- Hidratación adecuada.

- Uso de sanitario previo.

- Disponer de compañero que verifique la correcta colocación del EPP.

- En caso de tener cabello largo sujetarlo hacia atrás. 
- Retirar joyas, reloj y otros accesorios innecesarios.

- Verificar que el EPP de la talla adecuada se encuentre disponible.

- Lavado de manos adecuado.

\section{- Colocación}

1. Colocación de botas: Colocar dos pares de botas impermeables. Asegurarse que todo el calzado quede cubierto hasta los tobillos. Guardar cualquier cinta para evitar enganches y/o tropiezos.

2. Higiene de manos: Uso de solución antiséptica adecuada y realizar adecuada higiene de manos.

3. Colocación de gorro: Asegurar que todo el cabello se encuentre cubierto.

4. Si usa lentes correctivos: Retirarlos antes de colocar el respirador. Limpiarlos con alcohol.

5. Colocación del respirador de alta eficiencia: Tomar el respirador por las ligas de sujeción. Colocar la parte convexa en la barbilla como soporte y tirar las ligas hacia atrás de la cabeza. Colocar la liga superior arriba de las orejas y la liga inferior sobre la nuca. Asegurar la mascarilla moldeándola sobre el puente nasal y maxilares. Realizar prueba de inspiración y espiración hasta que no haya fuga infraocular o hacia las porciones laterales del respirador.

6. Colocación de gorro: Colocar segundo gorro (en caso de no haber escafandra). Asegurarse que todo el cabello y orejas se encuentren cubiertos.

7. Si usa lentes correctivos: Colocarlos antes de colocar el visor o gafas de protección ocular.

8. Colocar protección ocular: Se prefiere el uso de visor. El visor debe cubrir barbilla, frente y parte anterior de las orejas. Asegurar el visor en la parte posterior de la cabeza.

Si no se cuenta con visor utilizar gafas. Tomar las gafas por las ligas. Colocar las gafas sobre la cara y tirar la liga hacia atrás de la cabeza. Asegurar las gafas en la parte posterior de la cabeza.

9. Higiene de manos: Uso de solución antiséptica adecuada y realizar adecuada higiene de manos.

10. Colocación de guantes: Colocar guantes internos no estériles. Utilizar la talla adecuada.

11. Colocación de bata: Asegurar el velcro del cuello y cinta externa de la cintura. No atar cinta interna. Comprobar que toda la espalda quede bien cubierta. Guardar cualquier cinta para evitar enganches.

12. Colocación de guantes estériles o largos: Colocar guantes externos estériles con técnica habitual, cubrir la empuñadura de la bata. Utilizar la talla adecuada.

\section{En caso de procedimiento estéril:}

13. Higiene de manos: Uso de solución antiséptica adecuada y realizar adecuada higiene de manos sobre los guantes.

14. Colocación de bata: Colocar bata quirúrgica estéril con técnica habitual. Ayuda para asegurar velcro del cuello y cinta en la cintura.

15. Colocación de guantes estériles: Colocar guantes estériles con técnica habitual. Utilizar la talla adecuada.

\section{Retiro sistemático del equipo de protección per- sonal}

Se recomienda el uso de la lista de verificación en todos los pasos, misma que se encontrará en un lugar visible dentro del área designada para el retiro del EPP, así como realizar el retiro en parejas para optimizar la verificación de los pasos[7],[8],[11]-[15].

\section{- Equipo necesario}

- Solución antiséptica para higiene de manos.

- Solución desinfectante en recipiente adecuado para visor o gafas reutilizables.

- Contenedor grande adecuado para descartar equipo de un solo uso.

- Ambiente amplio.

\section{- Antes del retiro}

- Mantener una conducta tranquila, calmada y con movimientos lentos.

- Disponer de compañero que verifique el correcto retiro del EPP a una distancia mínima de 2 metros.

- Higiene de manos adecuado.

\section{- Retiro del equipo}

El retiro del EPP se realizará en las áreas designadas para ello, excepto en el caso de traslado del paciente postoperado, donde se realizará el retiro (pasos 1-4) y recolocación de bata y guantes externos dentro de quirófano o en un quirófano sucio designado para esta actividad. Y se realizará el retiro del EPP al finalizar el traslado del paciente (pasos 1-20).

Dentro de quirófano o en el quirófano sucio utilizado para esta actividad:

1. Retiro de botas: Sentarse y retirar botas externas con movimientos hacia adelante y abajo. Desechar en contenedor amplio sin empujar hacia abajo, con la finalidad de evitar aerosoles.

2. Higiene de manos: Uso de solución antiséptica adecuada y realizar adecuada higiene de manos sobre los guantes.

3. Retiro de bata quirúrgica y guantes externos: Liberar el velcro del cuello con asistencia. Desamarrar la cinta de la cintura y retirar la bata hacia adelante y abajo, con plegamiento de esta, dejar la parte externa (contaminada) hacia adentro. Retiro de 
guantes con plegamiento de estos, dejar la parte externa (contaminada) hacia adentro. Desechar en contenedor amplio sin empujar hacia abajo, con la finalidad de evitar aerosoles.

4. Higiene de manos: Uso de solución antiséptica adecuada y realizar adecuada higiene de manos sobre los guantes.

\section{Pasar al área de retiro de EPP dentro de quirófa-} no para esta actividad:

5. Retiro de protección ocular: Cerrar los ojos y hacer la cabeza hacia adelante del cuerpo. Si utiliza visor, tomar las ligas por la parte posterior de la cabeza y con movimientos suaves llevarlo hasta la parte superior de la cabeza. Retirar hacia adelante y abajo. Si el equipo es reutilizable colocar en solución desinfectante o descartar si es de un solo uso.

Si utiliza gafas, tomar las ligas por la parte posterior de la cabeza y con movimientos suaves llevarlo hasta la parte superior de la cabeza. Retirar hacia adelante y abajo. Colocar en solución desinfectante.

6. Higiene de manos: Uso de solución antiséptica adecuada y realizar adecuada higiene de manos sobre los guantes.

7. Retiro del gorro: Retirar el gorro externo tomándolo de la parte superior y retirar hacia atrás y hacia abajo. Desechar en contenedor amplio sin empujar hacia abajo, con la finalidad de evitar aerosoles.

8. Higiene de manos: Uso de solución antiséptica adecuada y realizar adecuada higiene de manos sobre los guantes.

9. Retiro del respirador de alta eficiencia: Cerrar los ojos y boca, hacer la cabeza hacia adelante del cuerpo. Tomar las ligas del respirador por la parte de atrás de la cabeza y con movimientos suaves llevarlo hasta la parte superior de la cabeza. Retirar hacia adelante y abajo. No tocar la parte externa del respirador. Desechar en contenedor amplio sin empujar hacia abajo, con la finalidad de evitar aerosoles.

10. Higiene de manos: Uso de solución antiséptica adecuada y realizar adecuada higiene de manos sobre los guantes.

11. Retiro del gorro: Retirar el gorro interno tomándolo de la parte superior y retirar hacia atrás y hacia abajo. Desechar en contenedor amplio sin empujar hacia abajo, con la finalidad de evitar aerosoles.

12. Higiene de manos: Uso de solución antiséptica adecuada y realizar adecuada higiene de manos sobre los guantes.
13. Retiro de botas: Retirar botas internas con movimientos hacia adelante y abajo. Desechar en contenedor amplio sin empujar hacia abajo, con la finalidad de evitar aerosoles.

Salir de quirófano para esta actividad:

14. Salir del área de quirófano previa limpieza de la suela de los zapatos con plástico adherente o campo húmedo con solución antiséptica adecuada.

15. Retiro de guantes: Retirar guantes internos con plegamiento de estos, dejar la parte externa (contaminada) hacia adentro. Desechar en contenedor amplio sin empujar hacia abajo, con la finalidad de evitar aerosoles.

16. Lavado de manos: Realizar lavado de manos adecuado con jabón y no menos de 20 segundos con todos los pasos recomendados por la OMS.

17. Si usa lentes: Cerrar los ojos y boca, hacer la cabeza hacia adelante del cuerpo. Tomar las patas de la parte distal y con un movimiento suave retirar hacia adelante y abajo. Limpiar con alcohol y recolocar posteriormente.

\section{Pasar al área de duchas para esta actividad:}

18. Retiro de uniforme hospitalario: Hacer la mitad del cuerpo hacia adelante, cerrar los ojos y boca. Retirar camisa tomándola del cuello posterior y halar hacia adelante y hacia abajo hasta retirarla. Desechar en contenedor amplio sin empujar hacia abajo, con la finalidad de evitar aerosoles. Desatar zapatos y pantalón y retirar ambos con movimientos lentos. Desechar el pantalón en el contenedor de la misma manera. Retirar ropa interior y colocar en sitio asignado junto con otro uniforme hospitalario limpio.

19. Ducha: Desatar cabello e ingresar a la ducha. Cerrar los ojos y boca. Realizar lavado habitual con énfasis en cara, cuello, nuca, antebrazos, brazos y manos.

20. Cambio de ropa: Vestirse con uniforme hospitalario limpio y sujetar cabello nuevamente. Colocar zapatos evitando tocar la suela o parte lateral.

\section{Cambios en el lugar y ambiente de trabajo}

\section{Cambios en el personal}

Se debe limitar el movimiento del personal sanitario dentro del área hospitalaria, restringiéndolo a su área de trabajo.

Se deben gestionar otras alternativas para realizar evaluaciones, interconsultas $u$ otra actividad fuera del servicio del personal, por medio de llamadas, videollamadas o designar a una persona con un horario compatible con la menor cantidad de flujo de personas que transitan. 
Se debe limitar el personal dentro de quirófano y terapias, evitar la participación de ayudantes, pasantes u observadores dentro de estas áreas. Se debe trabajar con pequeños grupos multidisciplinarios de trabajo, con el mínimo recurso humano necesario para realizar sus funciones (anestesia, cirujano, terapista, enfermería, suministros, intendencia, etc.) y en turnos establecidos para reducir el contacto entre el personal de cada grupo de trabajo. Se debe limitar, e inclusive restringir el ingreso y egreso continuo de las personas que laboran dentro de quirófano o terapia.

Al realizar procedimientos que generan aerosoles se debe limitar el personal dentro de la unidad (quirófano o terapia) a dos médicos con experiencia en el procedimiento por realizar y una enfermera circulante (Figura 1).

Todo el personal sanitario debe tener un registro escrito de la temperatura corporal al ingreso y egreso de sus labores, éste será anotado en una bitácora especial; asimismo, deberá notificar inmediatamente a su jefe superior si inicia con síntomas respiratorios o ha estado en contacto con pacientes sospechosos o positivos de SARS-CoV-2 sin el adecuado uso de EPP[7],[8],[10]-[16].

\section{Sobre los cambios en el quirófano y terapia intensiva}

Por normativa internacional las áreas correspondientes a terapia intensiva y quirófanos tienen ven- tilación que permite la presión positiva dentro de las mismas, así como tres filtros escalonados, uno de los cuales debe ser tipo detención de partículas de alta eficiencia (HEPA) en la entrega de la ventilación[17],[18].

El departamento de mantenimiento hospitalario debe contar con una bitácora de verificación de las evaluaciones preventivas cada 6 meses máximo y cambio de filtros una vez al año. Además, se debe solicitar el cambio en la ventilación dentro de las áreas de quirófano y terapia con presión negativa y la colocación de filtros en la extracción de la ventilación, esta es la misma disposición que se utiliza en sitios contaminados como áreas de microbiología y aislamiento[17],[18].

Se debe retirar todo el equipo que no se utilice regularmente dentro del área de quirófano o terapia. Ejemplo: fluoroscopio portátil, máquina de ecocardiografía, carros de equipo, etc. El equipo que se utilice regularmente se debe proteger con fundas o bolsas que permitan una desinfección fácil y adecuada de superficies[7],[8],[10]-[15].

\section{Manejo de la vía aérea}

\section{Procedimientos que generan aerosoles (PGA)}

Los siguientes son considerados PGA[9],[19]-[21]:

- Intubación, extubación y procedimientos relacionados (ventilación manual y succión abierta del tracto respiratorio).

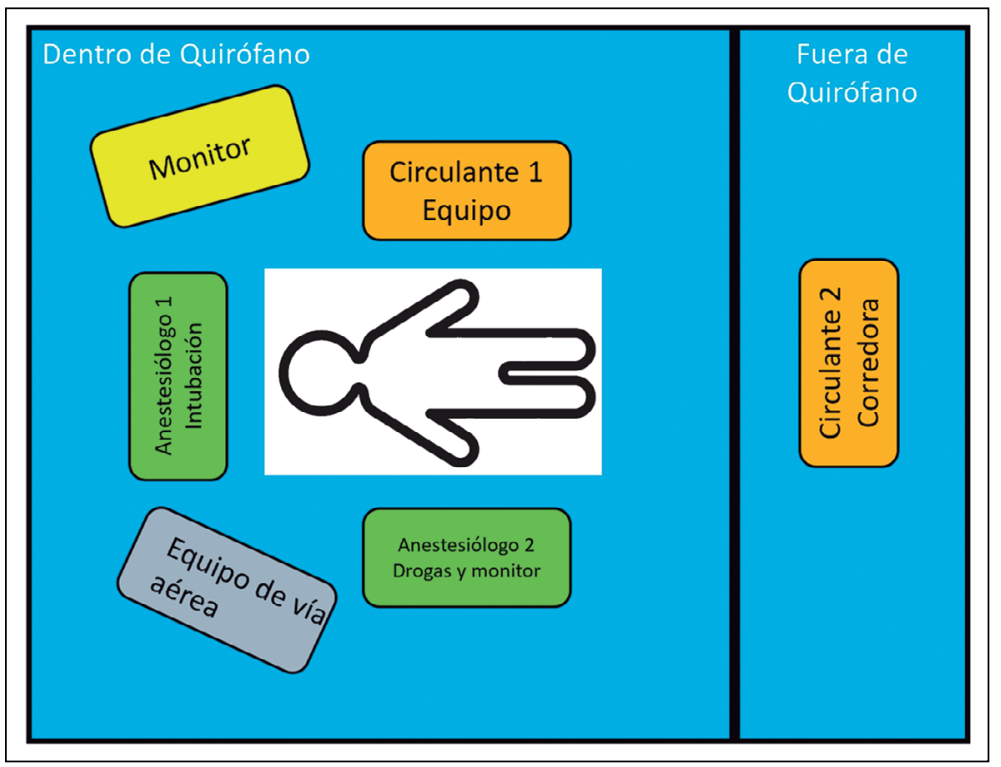

Figura 1. Ubicación del personal y equipo en procedimientos que generan aerosoles. Fuente: Modificado de Cook, T. M. Anesthesia. 2020[10]. 
- Procedimientos en traqueostomía o traqueotomía (inserción, succión o extracción abiertas).

- Broncoscopia y procedimientos de otorrinolaringología de la vía aérea superior que implican aspiración.

- Endoscopia gastrointestinal superior donde hay una succión abierta o insuflación del tracto respiratorio superior.

- Cirugía y procedimientos post mortem con dispositivos de alta velocidad (uso de sierras eléctricas).

- Algunos procedimientos dentales (perforación con fresas o taladros de alta velocidad).

- Ventilación no invasiva: Ventilación de presión positiva de dos vías en las vías respiratorias (BiPAP) y ventilación de presión positiva continua en las vías respiratorias (CPAP), puntas nasales de alto flujo.

- Ventilación oscilatoria de alta frecuencia (HFOV).

- Inducción de esputo (tos).

- Compresiones torácicas durante la reanimación cardiopulmonar[19].

Los PGA deben ser realizados en una habitación individual con las puertas cerradas. Solo debe estar presente el personal esencial para llevar a cabo el procedimiento y con EPP de alta eficiencia bajo las recomendaciones previamente establecidas.

Existen otros procedimientos, pueden generar dispersión de las secreciones del paciente y que no se consideran con riesgo infeccioso significativo, aunque deben ser manejados con EPP y son: colocación de sonda nasogástrica, manejo de secreciones oculares, sangre, heces y orina, así como la colocación de sonda de ecocardiograma transesofágico, la cual debido a su importancia en la cirugía cardiovascular pediátrica se aborda a continuación[8],[9],[21].

\section{Ecocardiografía transesofágica (ETE)}

La realización de ETE debe ser pospuesto o cancelado si no es estrictamente necesario. Debe participar solo el personal que lo realiza, con un asistente si es fuera de quirófano; y con un protocolo previsto que permita realizar un estudio completo en el menor tiempo posible.

No es claro el papel de la ETE en la diseminación de aerosol por la colocación y uso de la sonda, pero debido a que en el contexto de la anestesia cardíaca pediátrica esta es colocada inmediatamente después de la intubación, debe considerarse como PGA[21].

La Sociedad Americana de Ecocardiografía emitió las siguientes recomendaciones en cuanto al tipo de protección del que realizará la ETE[21]:

- Equipo y protección estándar: Lavado o higiene de manos y uso de guantes descartables.

- Protección contra gotas: Uso de bata impermea- ble, guantes descartables, botas (si es en el quirófano), cubre bocas quirúrgico y protección ocular. - Protección contra aerosoles: Agregar a lo anterior máscara N95 o superiores y botas. Esto en casos sospechosos o comprobados de infección por SARS-CoV-2 por el riesgo de aerosol.

El EPP está relacionado al tipo de procedimiento (transtorácico o transesofágico) y sitio de realización (laboratorio de ecocardiografía, hospitalización, urgencia, hemodinamia, Unidad de Terapia Intensiva o quirófano)[21] (Figura 2).

El equipo de ecocardiografía será protegido con plástico o cobertores que permitan su desinfección adecuada posterior a la realización del estudio.

La sonda de ETE debe seguir un proceso de lavado en el área quirúrgica y posteriormente se trasladará en un contenedor cerrado al sitio donde se desinfectará de acuerdo con las indicaciones del proveedor y normas hospitalarias bioinfecciosas.

\section{Equipo y material necesario para el manejo de la vía aérea (VA)}

El equipo y material necesario para el manejo de la VA será enumerado en una lista, considerar la disponibilidad y acceso del servicio donde se realizan los PGA. El equipo de monitoreo recomendado será acorde al escenario y protocolo de cada unidad, asegurar el monitoreo estándar de la Sociedad Americana de Anestesiología y un capnógrafo[10]-[15].

El equipo corresponderá a las necesidades de cada paciente, guiados por edad y peso y debe ser útil para el manejo previsto de la VA y en el caso de una VA difícil no anticipada. Un elemento necesario para el manejo de la VA es el reservorio para la colocación de material y equipo contaminado; se recomienda el uso de una bolsa con doble cierre para equipo reutilizable y depósito para el equipo desechable, esto según la norma hospitalaria de desinfección y desechos de bioinfecciosos[14],[20]-[22].

\section{Planeación para el manejo de la VA difícil}

Es recomendable que la lista de verificación para la planeación del manejo de la VA difícil sea realizada por el equipo multidisciplinario involucrado con el cuidado del paciente en el quirófano o terapia intensiva[7],[10]-[14].

Se recomienda la intubación orotraqueal como primera línea del manejo de la VA, seguido por el uso de mascarilla laríngea de segunda o tercera generación.

La planeación debe ser individualizada y orientada hacia cada caso en particular, para poder actuar de manera oportuna. Dentro del algoritmo de acción se 


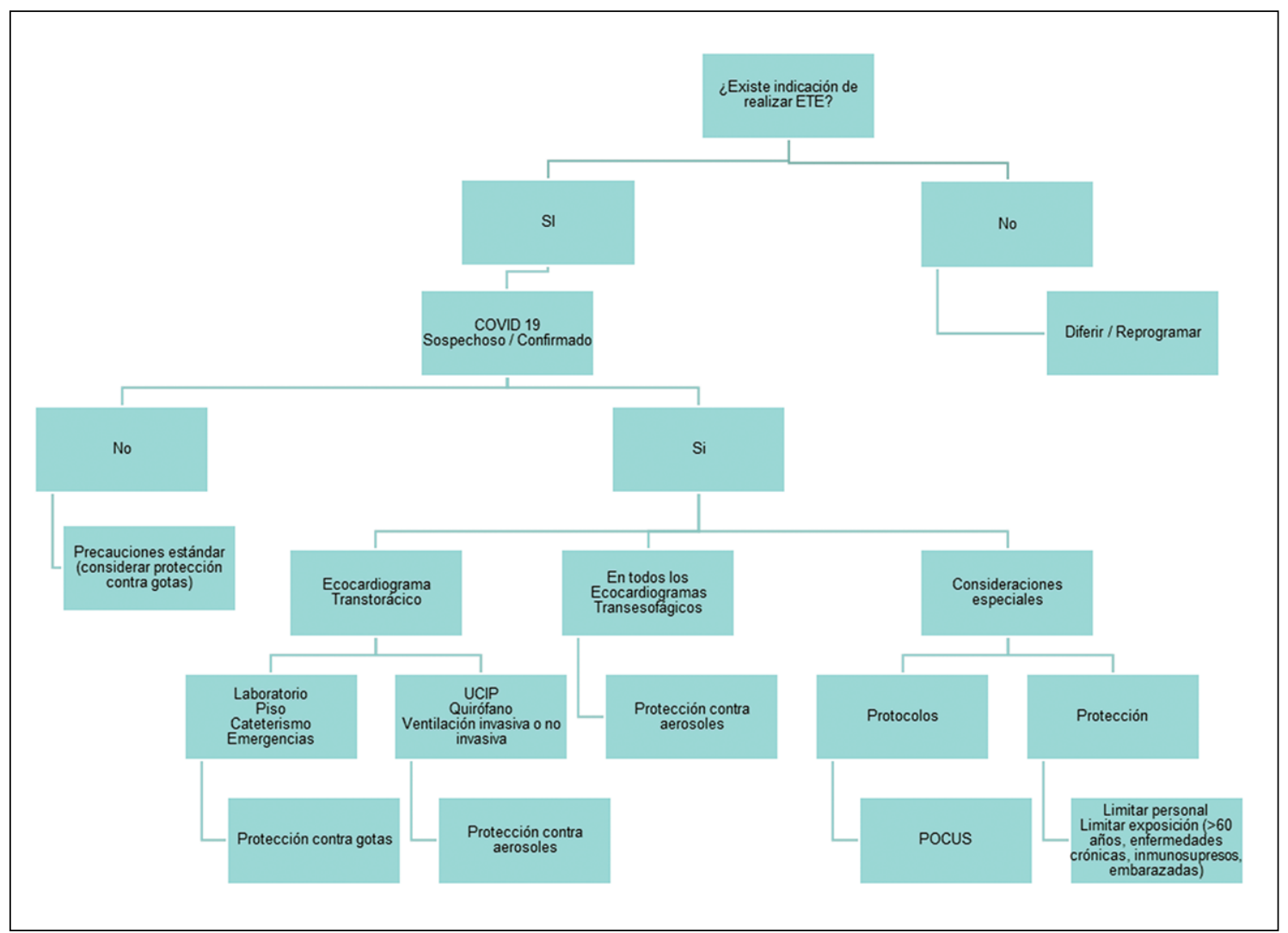

Figura 2. Algoritmo para determinar el nivel de protección del personal que realiza el estudio de ecocardiografía. Abreviaturas: ETE: Ecocardiografía transesofágica; UCIP: Unidad de Terapia Intensiva Pediátrica; POCUS: Ecografía en el punto de atención. Fuente: Modificado de ASE Statement on Protection of Patients and Echocardiography Service Providers During the 2019 Novel Coronavirus Outbreak[21].

contemplará la opción de despertar al paciente o continuar el algoritmo habitual de manejo de la VA difícil hasta la traqueostomía de urgencia. Es controversial la inclusión del uso de fibrobroncoscopio al algoritmo de manejo de la VA difícil debido a la generación de aerosoles[13],[14].

\section{Protocolo de intubación[7],[10]-[15]}

a. EPP

El personal involucrado (dos médicos expertos y una enfermera circulante) deben tener el EPP de alta eficiencia correctamente colocado.

El paciente y familiar (tutor o encargado) deben usar una mascarilla quirúrgica.

\section{b. PLAN}

Se recomienda que cada integrante se familiarice con las actividades para alternar los pasos y evitar duplicar acciones que puedan provocar accidentes o contaminación.

El plan de manejo debe discutirse previamente con todo el equipo y comprobarse en la lista de verificación. En este plan se asignará al líder y los roles de los participantes. Se designará a una enfermera circulante fuera del área del procedimiento para contactar ayuda en caso sea necesario. Además, se planeará el manejo del equipo, monitoreo y material utilizado en el manejo de la VA prevista y VA difícil.

\section{c. PREPARACIÓN}

El monitoreo, equipo, material y medicamentos necesarios deben estar listos y disponibles dentro del área de intubación. Considerar las alergias, peso, edad y talla del paciente para esto. Además, preparar material dispuesto para probable manejo de VA difícil. 


\section{d. PREOPERATORIO}

Consentimientos y evaluación preoperatoria se realizarán previamente y no ingresarán a quirófano o sala de intubación.

Se continuará con el protocolo habitual de la descolonización del paciente previo al procedimiento quirúrgico (limpieza corporal con toallas de clorhexidina, enjuague bucal con clorhexidina, limpieza nasal con povidona yodada).

Para pacientes quirúrgicos, uno de los anestesiólogos premedicará al paciente pediátrico previo al traslado a quirófano con dosis plenas de benzodiacepina, y/o ketamina o dexmedetomidina si existe inestabilidad hemodinámica, se colocará monitoreo y uso de oxígeno suplementario por cánula nasal bajo la mascarilla quirúrgica.

\section{e. PREVIO A INTUBACIÓN}

- Monitorizar al paciente.

- Verificar acceso endovenoso.

- Optimizar la posición del paciente.

- Optimizar la hemodinamia del paciente (terapia hídrica, vasopresor, inotrópicos, etc.).

\section{f. INTUBACIÓN}

- Preoxigenar durante 5 minutos con mascarilla facial acojinada, con técnica de sello V-E (Figura 3).

- Evitar ventilar con presión positiva. En pacientes con poca reserva pulmonar o inestabilidad hemodinámica, se recomienda usar PEEP de 4-5 $\mathrm{cmH}_{2} \mathrm{O}$ o ventilar con volúmenes tidales bajos.

- Utilizar inducción de secuencia rápida.

- Se recomienda el uso de video-laringoscopio se encuentra disponible y el personal se encuentra familiarizado con su uso.
- Inflar el globo del tubo orotraqueal bajo visión directa.

g. MANEJO DEL EQUIPO Y MATERIAL CONTAMINADO

- Posterior a la intubación se descartará la mascarilla facial acojinada, cánula orofaríngea (si fue utilizada), hoja desechable de video laringoscopio. El mango de video laringoscopio reutilizable se colocará en una bolsa de doble cierre especial para este equipo.

- El médico que realizó la intubación se realizará higiene de manos con solución antiséptica, retirará guantes externos, los descartará en el reservorio adecuado. Realizará higiene de manos con solución antiséptica en guantes internos y se colocará nuevamente un segundo par de guantes externos.

\section{h. VERIFICACIÓN DE LA INTUBACIÓN}

- Inmediato a la intubación el médico ayudante verificará la distancia en la que quedó el tubo respecto a la comisura bucal según la edad o peso del paciente.

- Se conectará al circuito de ventilación, previa verificación del inflado del balón del tubo orotraqueal y se buscará onda de capnografía. Evitar la verificación con estetoscopio a fin de disminuir el uso de fomites, la contaminación del EPP y el aproximarse a la vía aérea recién intubada.

\section{i. FIJACIÓN}

- Se fijará el tubo de manera convencional.

- Se colocarán gasas en carrillos, siempre que no se deba introducir sonda de ETE.

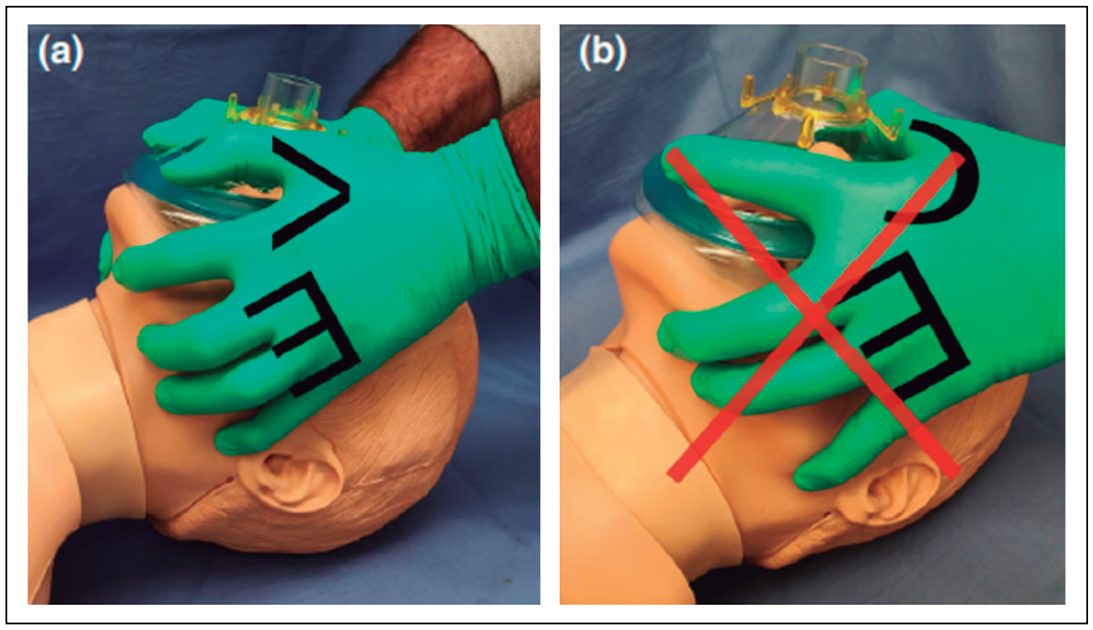

Figura 3. Técnica $V$-E para el sellado adecuado de la vía aérea. Fuente: Tomado Cook TM, El-Boghdadly K, McGuire $B$, McNarry AF, Patel A, Higgs A. Consensus guidelines for managing the airway in patients with COVID-19. Anaesthesia. 2020 Mar 27. doi: 10.1111/ anae. 15054[10]. 
- Se colocarán parches oculares y se fijarán gasas sobre estos, con el fin de contener lágrimas o secreciones oculares (Figura 4).

- Limitar las desconexiones innecesarias del circuito de ventilación.

\section{Protocolo de extubación[7],[10]-[16]}

a. EPP

El personal involucrado (dos médicos expertos y una enfermera circulante) deben tener el EPP de alta eficiencia correctamente colocado.

b. PLAN

El plan de manejo debe discutirse previamente con todo el equipo y comprobarse en la lista de verificación. En este plan se asignará al líder y los roles de los participantes. Se designará a una enfermera circulante fuera del área del procedimiento para contactar ayuda en caso sea necesario. En los pacientes quirúrgicos, se recomienda plan de extubación y recuperación dentro del quirófano. Además, se planeará el manejo del equipo, monitoreo y material utilizado en la recuperación y traslado del paciente.

Debe ser considerado tener disponible el equipo del manejo de la VA prevista y VA difícil en caso de una extubación fallida.

\section{PREPARACIÓN}

El monitoreo, equipo, material y medicamentos necesarios deben estar listos y disponibles dentro del área de extubación. Considerar las alergias, peso, edad y talla del paciente para esto. Además, preparar material dispuesto para probable reintubación, considerar el equipo de VA difícil.

d. PREVIO A EXTUBACIÓN

- Monitorizar al paciente.

- Verificar acceso endovenoso.

- Optimizar la posición y sujeción del paciente.

- Optimizar la analgesia, sedación y medicamentos antieméticos.

- Optimizar el patrón ventilatorio del paciente (aspiración endotraqueal con sistema cerrado, aspiración de carrillos con Yankauer, nebulización, etc.)

e. EXTUBACIÓN

- Desinflar el balón.

- Evitar extubación con presión positiva o PEEP.

- Retirar el tubo orotraqueal sin desconectarlo del circuito de ventilación.

- Inmediatamente después de retirado el tubo orotraqueal colocar una compresa o campo sobre la VA que permita la ventilación espontánea del paciente y evite la expulsión de aerosoles o gotas si tose.

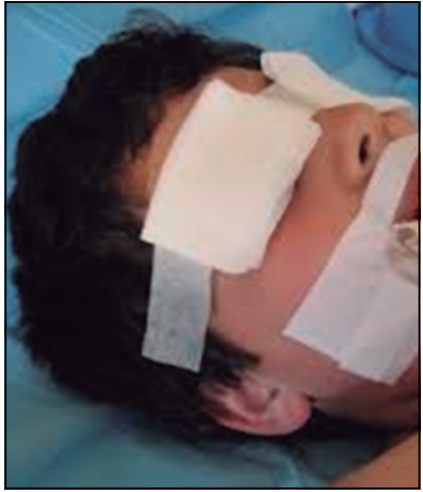
de gasas sobre parches oculares. Fuente: Colección del autor.
Figura 4. Colocación

f. MANEJO DEL EQUIPO Y MATERIAL CONTAMINADO

- El médico que realizó la extubación se realizará higiene de manos con solución antiséptica, retirará guantes externos, los descartará en el reservorio adecuado. Realizará higiene de manos con solución antiséptica en guantes internos y se colocará nuevamente un segundo par de guantes externos.

- Mientras el médico auxiliar descartará el tubo orotraqueal en un reservorio especial para este equipo.

- Colocar la mascarilla facial acojinada al circuito de ventilación.

\section{g. RECUPERACIÓN}

- El médico auxiliar colocará la mascarilla facial acojinada en el paciente con técnica $V$-E, evaluar la adecuada ventilación espontánea.

- Si el paciente se encuentra estable, se colocarán puntas nasales y una mascarilla quirúrgica sobre estas, cubrir la boca y nariz del paciente.

\section{Manejo y desinfección del quirófano y equipo}

\section{Máquina de anestesia}

Se recomienda utilizar dos filtros de detención de partículas de alta eficiencia (HEPA), en la conexión de la rama espiratoria del circuito de ventilación y la máquina de anestesia, y en la conexión del circuito al paciente[14],[16],[18],[20]-[23].

Se recomienda utilizar un filtro de intercambio de calor y humedad (HMEF) en la conexión del circuito al paciente, y de no contar con él se debe disminuir el flujo de gas fresco a 1-2 L o menos, para preservar la humedad[14],[18]. 
Hay que considerar que los filtros pediátricos HMEF son filtros electrostáticos con baja eficiencia de filtración viral (VFE). Además, valorar el espacio muerto aceptable para pacientes pequeños, especialmente en menores de $5 \mathrm{~kg}$.

Si la línea de capnógrafo no tiene una VFE efectiva, será seguro colocar un filtro epidural de 0,2 micrones en la entrada de la trampa de agua. Hay que considerar que la calidad de la capnografía puede ser afectada[14],[18].

Si la línea de capnógrafo y la trampa de agua no fue protegido con una VFE deben ser descartados después de su uso con cada paciente, así como el circuito de ventilación.

No existe evidencia de que la cal sodada deba ser cambiada siempre que se haya utilizado el filtro de alta eficiencia en la rama espiratoria[14],[16],[18].

\section{Quirófano, mobiliario y monitoreo}

Después de la intubación se recomienda realizar una desinfección de las superficies del equipo y mobiliario expuesto con toallas con solución de amonio cuaternario y alcohol[14],[16]-[18],[22], o con cualquiera de los agentes biocidas que inactivan el virus SARS-CoV-2 mencionados anteriormente[6].

Se ha sugerido el uso de cobertores de plástico sobre monitores, carros de suministros o máquina de anestesia, aunque la posibilidad de contaminación del personal, equipo o quirófano al retirarse es desconocido[14].

Idealmente se deberá descontaminar con luz ultravioleta (20-30 minutos) y soluciones antisépticas para las superficies y piso. Las soluciones antisépticas con compuesto de amonio cuaternario y alcohol son altamente recomendadas[14],[18],[21],[23].

Desinfectar todos los puntos de contacto del anestesiólogo, como los monitores, vaporizadores, válvula $\mathrm{APL}$, atriles, carros de suministros, control de la mesa quirúrgica, así como cada cable del monitoreo del paciente.

Se debe considerar los cambios de aire por hora (CAH) que tiene cada quirófano para iniciar la limpieza terminal después de egresado el paciente, por norma internacional deberá tener mínimo $15 \mathrm{CAH}$. El Centro del Control de las Enfermedades de EE. UU. (CDC) recomienda el tiempo requerido para la eficiente eliminación de contaminantes según los recambios de aire por hora, aproximadamente 30 minutos, aunque aún no se conoce con exactitud el tiempo que el virus puede permanecer suspendido en el ambiente $[14],[17],[22]$.

\section{Equipo reutilizable de la vía aérea}

Es altamente recomendable utilizar equipo descartable y de un solo uso siempre que sea posible y deberá desecharse como fue mencionado anteriormente. De lo contrario, el equipo debe ser esterilizado (autoclave), y de no ser posible se realizará desinfección química[14],[16],[17],[22],[23].

El departamento de prevención de infecciones nosocomiales recomendará el tipo de desinfección para el equipo reutilizable del manejo de la VA.

\section{Traslado de paciente[7],[10]-[16]}

a. EPP

El personal involucrado (médico y enfermero) deben tener el EPP de alta eficiencia correctamente colocado.

\section{b. PLAN}

El plan de manejo debe discutirse previamente con todo el equipo y comprobarse en la lista de verificación. En este plan se asignará al líder y los roles de los participantes.

Los pacientes que serán operados de cirugía cardíaca serán trasladados directamente al quirófano designado sin pasar por la unidad preanestésica, por un anestesiólogo y un enfermero.

Los pacientes posoperados de cirugía cardíaca serán trasladados por un anestesiólogo, un cirujano y un enfermero.

Durante el traslado de pacientes hacia otros servicios, estudios de imagen u otros, se deben tener las mismas consideraciones descritas en el traslado de pacientes posoperados.

Además, se planeará el manejo del equipo, monitoreo y material utilizado en el traslado del paciente. Debe considerar tener disponible el equipo del manejo de la VA prevista y VA difícil, en caso de una extubación accidental o deterioro del patrón respiratorio en pacientes extubados.

\section{c. PREPARACIÓN}

El monitoreo, equipo, material y medicamentos necesarios deben estar listos y disponibles para transportar durante todo el traslado. Considerar las alergias, peso, edad y talla del paciente para esto. Además, preparar material dispuesto para posible reintubación. Durante el traslado, los pacientes intubados deben tener un filtro de intercambio de calor y humedad (HMEF) o de alta eficiencia (HEPA) insertado entre la bolsa autoinflable y el paciente en todo momento. Los pacientes no intubados deben continuar el uso de su mascarilla o respirador sobre el dispositivo de flujos bajos de oxígeno[14],[16]. 
d. PREVIO AL TRASLADO

- Monitorizar al paciente y verificar batería de los equipos.

- Verificar acceso endovenoso.

- Optimizar la posición y sujeción del paciente.

- Optimizar la analgesia, sedación y medicamentos antieméticos.

- Optimizar el patrón ventilatorio del paciente (aspiración endotraqueal con sistema cerrado, aspiración de carrillos con yankauer, nebulización, etc.).

h. TRASLADO

- Trasladar al paciente sospechoso o confirmado de infección por el virus SARS-CoV-2 por accesos (pasillos y elevadores) designados para este tipo de paciente.

- Evitar tocar superficies ambientales durante el traslado, como los botones del elevador, puertas o manijas[14].

- En pacientes ventilados se debe evitar desconexiones innecesarias del tubo orotraqueal y la bolsa autoinflable. De ser necesario, se debe pinzar el tubo antes de la desconexión, con el fin de disminuir la producción de aerosoles[7],[10]-[15].

\section{i. ENTREGA}

- Se monitorizará y colocará en ventilador mecánico con los mismos parámetros ventilatorios de quirófano en el caso de paciente intubado, o se colocará a una toma de oxígeno para flujos bajos en caso de paciente extubado.

- Se colocará la bolsa de autoinflado en una bolsa plástica de doble cierre especial para este equipo según la norma hospitalaria de manejo de bioinfecciosos para el uso del mismo paciente.

- Se entregará al médico de la terapia intensiva cardiovascular pediátrica o al médico encargado del servicio correspondiente, según el algoritmo de entrega del hospital.

- Se discutirá el plan inmediato y recomendaciones de cuidado del paciente.

\section{Apoyo económico}

Este estudio fue realizado con recursos departamentales.

\section{Conflicto de intereses}

Ninguno.

\section{Referencias}

1. Zaho S, Ling $K$, Yan $H$, Zhong $L$, Peng $X, Y$ Yo $S$, et al. Anesthetic management of patients with suspected or confirmed COVID. Novel Coronavirus Infection During Emergency Procedures.J Cardiovasc Vasc Anesth; 2019. https://doi.org/10.1053/j. jvca.2020.02.039.

2. World Federation of Societies of Anaesthesiology. Coronavirus - guidance for anaesthesia and perioperative care providers. http://wfsa.org

3. Wax RS, Christian MD. Practical recommendations for critical care and anesthesiology teams caring for novel coronavirus (2019-nCoV) patients. Canadian Journal of Anesthesia/Journal canadien d'anesthésie. Springer Science and Business Media LLC; 2020 Feb 12;67(5):568-76. http://dx.doi.org/10.1007/ s12630-020-01591-x.

4. The Children's Hospital Association of the United States. Pediatric Elective Surgery/ Procedure Guidance. Marzo 23, 2020. http://childrenshospitals. org/-/media/Files/CHA/Main/ Quality_and_Performance/ covid19/covid_032320_cha_ pediatric_elective_surgery_ guidance.pdf

5. Dong $Y$, Mo X, Hu Y, Qi $X$, Jiang $F$, Jiang $Z$, et al. Epidemiology of COVID-19 Among Children in China. Pediatrics. American Academy of Pediatrics (AAP); 2020 Mar 16;e20200702. https://doi. org/10.1542/peds.2020-0702 PMID:32179660

6. Zimmermann P, Curtis N. Coronavirus Infections in Children Including COVID-19. An Overview of the Epidemiology, Clinical Features, Diagnosis, Treatment and Prevention Options in Children. Pediatr Infect Dis J. 2020;39(5):355-68. https://doi.org/10.1097/ INF.0000000000002660.

7. SEDAR. Documento consenso recomendaciones anestesia pediátrica sección anestesia pediátrica. 2020. https:// www.sedar.es/images/site/ BIBLIOGRAFIA_COVID-19/ Pediatria/DOC_SEDAR_ Documento \%20concenso $\% 20$ anestesia\%20pediatrica.pdf

8. Intensive Care Society. COVID-19 Information for ICS Members. 2020. https:// www.ics.ac.uk/COVID19. aspx?hkey $=$ d176e2cfd3ba-4bc7-843549bc618c345a\&WebsiteKey= 10967510-ae0c-4d85-8143a62bf0ca5f3c

9. Public Health England. COVID-19 personal protective equipment (PPE). 2020. https:// 
www.gov.uk/government/ publications/wuhan-novelcoronavirus-infectionprevention-and-control/ covid-19-personal-protectiveequipment-ppe (accesado 01/04/2020).

10. Cook TM, El-Boghdadly K, McGuire B, McNarry AF, Patel A, Higgs $A$. Consensus guidelines for managing the airway in patients with COVID-19. Anaesthesia. Wiley; 2020 Apr 1; https://doi.org/10.1111/ anae.15054 PMID:32221970

11. de Sociedad E. Cirugía Pediátrica. Recomendaciones de la Sociedad Española de Cirugía Pediátrica para el manejo de pacientes pediátricos quirúrgicos en el contexto de la pandemia por COVID-19. 2020. https:// secipe.org/wordpress03/index. php/recomendaciones-de-lasociedad-espanola-de-cirugiapediatrica-para-el-manejode-pacientes-pediatricosquirurgicos-en-el-contexto-de-lapandemia-por-covid-19/

12. Wax RS, Christian MD. Practical recommendations for critical care and anesthesiology teams caring for novel coronavirus (2019-nCoV) patients. Can J Anaesth. 2020 Feb;67(5):1-9. https://doi.org/10.1007/s12630020-01591-x PMID:32052373

13. Greenland JR, Michelow MD, Wang L, London MJ. COVID-19 Infection. Anesthesiology. Ovid Technologies (Wolters Kluwer Health); 2020 Mar;1. http://dx.doi.org/10.1097/ aln.0000000000003303

14. London MJ. Coronavirus disease 2019 (COVID-19) patients: Airway management, anesthesia machine ventilation, and anesthetic care. Uptodate. 2020. https://www.uptodate. com/contents/coronavirusdisease-2019-covid-19-patientsairway-management-anesthesiamachine-ventilation-andanesthetic-care\#H2011106604

15. Coronavirus - guidance for anaesthesia and perioperative care providers. World Federeation of Societies of Anaesthesiologist. 2020. https:// www.wfsahq.org/resources/ coronavirus

16. American Society of Anesthesiologists Committee on Occupational Health. Coronavirus Information for Health Care Professionals (Clinical FAQs) https:// www.asahq.org/about-asa/ governance-and-committees/ asa-committees/committee-onoccupational-health/coronavirus/ clinical-faqs

17. Arnabat I. Recomendaciones de filtrado de aire y ventilación frente al coronavirus COVID-19. 2020. https://www.caloryfrio. com/construccion-sostenible/ ventilacion-y-calidad-aireinterior/recomendaciones-defiltrado-de-aire-y-ventilacionfrente-al-coronavirus-covid-19. html

18. Normas arquitectónicas de quirófano. España. 2020. https://www.quirofano.net/ normas-quirofano/normasarquitectura-quirofano.php

19. Asociación Americana del Corazón y Academia Americana de Pediatría. 2020. Interim guidance for pediatric resuscitation care to reduce COVID-19 transmission. https:// cpr.heart.org/-/media/cpr-files/ resources/covid-19-resources- for-cpr-training/interimguidance-pediatric-patientsmarch-27-2020.pdf?la=en\&hash =00F501EB7F4B5DA66DCE1CFE FF456DF147C 1AE63

20. FAQ on Anesthesia Machine Use, Protection, and Decontamination During the COVID-19 Pandemic American Society of Anesthesiologists committee on Occupational Health: Coronavirus Information for Health Care Professionals (Clinical FAQs) https://www. apsf.org/faq-on-anesthesiamachine-use-protection-anddecontamination-during-thecovid-19-pandemic/

21. Kirkpatrick JN, Mitchell C, Taub C, Kort S, Hung J, Swaminathan M. ASE Statement on Protection of Patients and Echocardiography Service Providers During the 2019 Novel Coronavirus Outbreak [published online ahead of print, 2020 Apr 6]. J Am Coll Cardiol. 2020;S0735-1097(20)34815-4. doi:10.1016/j.jacc.2020.04.002

22. Centers of Disease Control and Prevention. Guidelines for Environmental Infection Control in Health-Care Facilities (2003) https://www.cdc.gov/ infectioncontrol/guidelines/ environmental/appendix/air.html

23. Dexter F, Parra MC, Brown $J R$, Loftus RW. Perioperative COVID-19 Defense: An Evidence-Based Approach for Optimization of Infection Control and Operating Room Management [published online ahead of print, 2020 Mar 26]. Anesth Analg. 2020 Mar;1. https://doi.org/10.1213/ ANE.0000000000004829 PMID:32217947 